\title{
Environmental health damage factors assessment in brownfield redevelopment
}

\author{
L. Kliucininkas \& D. Velykiene \\ Department for Environmental Engineering, \\ Kaunas University of Technology, Lithuania
}

\begin{abstract}
Due to the lack of definite studies associated with exposure to the various chemicals that are found at brownfield sites, risk and damage assessment seems to represent an important foundation in the development of effective environmental management of brownfields. In order to derive integrated indicators for brownfield environmental health damage assessment authors applied Eco-indicators 99 method. The study shows that damage oriented database for Life Cycle Impact Assessment (LCA) could be applied to estimate degree of potential damage on human health and ecosystems quality. The particular example on damage factors derived for contamination by heavy metals is presented. Due to the high complexity of the issue, authors have limited case to the local effects on human health and ecosystem quality, i.e. contamination by heavy metals causes two categories of damages: carcinogenic effects on human health and degradation of ecosystem quality caused by ecotoxic emissions. The paper presents the application of the emda (emission+damage) vector approach to the integrated assessment of environmental health damage of brownfield redevelopment. The emda vector comprises quantitative and qualitative characteristics, i.e. emission and damage factors. Each emda vector combines three components: emission-damage factors for soil, water and air. The study gives prerequisites for further development of environment health damage assessment method.
\end{abstract}

Keywords: brownfields, human health, ecosystem quality, assessment of damage, emda vector. 


\section{Introduction}

Over the past decade, the value of redeveloping brownfields as a potential for reduction of urban sprawl has become one of the priorities in EU and other countries. Brownfield redevelopment is now seen as a sustainable land use strategy.

The overall objective of the remediation is always the protection of human health and the environment. Due to the lack of definite studies on the health risk associates with exposure to the various chemicals that are found at these sites, it has often been impossible to determinate to what level clean-up of brownfields should be achieved. In this regard, therefore, risk assessment seems to represent an important foundation in the development of effective environmental management of brownfields. Increasingly, policy makers, health risk managers and epidemiologists are using risk assessment techniques.

Emissions of dangerous substances from local sources can have impacts on the quality of soil and water, particularly groundwater. Management of contaminated sites aims at assessing the adverse effects caused and taking measures to satisfy environmental standards according to current legal requirements.

Management of contaminated sites is designed to ameliorate any adverse effects where impairment of the environment is suspected or has been proved, and to minimize any potential threats (to human health, water bodies, soil, habitats, foodstuffs, biodiversity etc.). Management starts with a basic desk study or historical investigation, which may lead to more detailed investigations, remediation or land redevelopment

Zhu and Hipel [1] proposed a framework for risk management in brownfield redevelopment projects (BRPs). This structure involves the three dimensions consisting of time, logic and knowledge. The time dimension is concerned with the initiation, planning, implementation and closure phases of the life span of a BRP. The logic dimension considers the processes of risk management comprised of risk identification, assessment and treatment, while the knowledge dimension furnishes tools and techniques which can be used in risk management of a BRP. By using this framework, risk management is integrated into the overall BRP management structure.

Feldman [2] reports functional elements of risk management contained in the site management plan (SMP). The case studies include subsequent property transfers of the shopping mall, the discoveries of affected soil within the mall footprint during the anticipated future changes in retail space allocations and space usage, and the efficient management of polluted soil during the anticipated construction of additions to the retail operations within the site.

The goal of corrective action at any site impacted with chemicals is to develop the most relevant, cost-effective and appropriate risk management option(s) that are protective of public health, water quality, and ecological health in both the short- and long- term. Environmental "look-up tables" that present potentially acceptable concentrations of chemicals (also called screening values) 
in soil, air and water media can expedite decision-making process for all the stakeholders involved [3].

\section{The EU policies towards brownfield redevelopment}

In EEA (European Economic Area) member countries, it is estimated that potentially polluting activities have occurred at about three million sites $[4,5]$. National estimates show that more than 8\% (or nearly 250000 sites) are contaminated and need to be remediated. Potentially polluting activities are estimated to have occurred at nearly 3 million sites (including the 250000 sites already mentioned) and investigation is needed to establish whether remediation is required. If current investigation trends continue, the number of sites needing remediation will increase by $50 \%$ by 2025 .

By contrast, more than 80000 sites have been cleaned up during the last 30 years in the countries where data on remediation is available. Although the range of polluting activities (and their relative importance as localised sources of soil contamination) may vary considerably across Europe, industrial and commercial activities as well as the treatment and disposal of waste are reported to be the most important sources, fig. 1. Although considerable efforts have been made already, it will take decades to clean up a legacy of contamination.

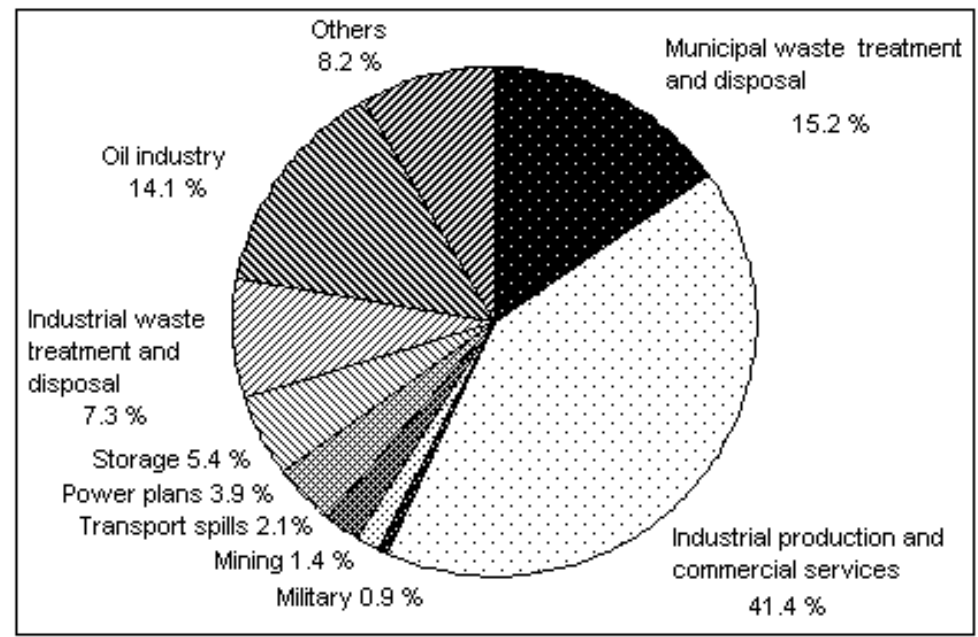

Figure 1: Overview of activities causing soil contamination in Europe.

The range of contaminants found in the investigated sites varies from country to country. However, overall estimates identify heavy metals and mineral oil as the main soil contaminants in Europe. These estimates are based on the frequency with which a specific contaminant is reported to be the most important in the investigated sites. Other contaminants include polycyclic aromatic hydrocarbons (PAH), aromatic hydrocarbons (BTEX), phenols and chlorinated 


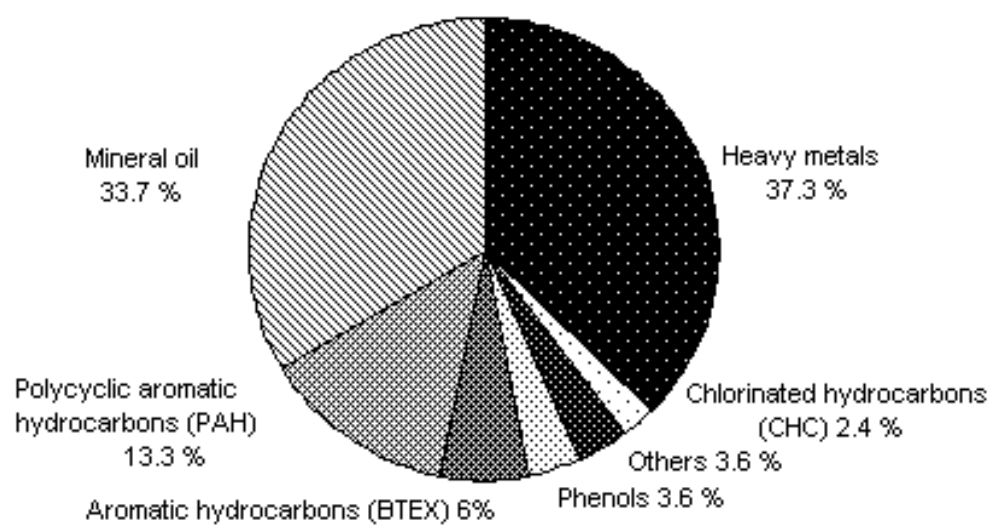

Figure 2: Overview of contaminants affecting soil and groundwater in Europe.

hydrocarbons (CHC), fig. 2. Mineral oil and heavy metals are reported as the most relevant contaminants for groundwater.

The European Union and its member states provide different public incentives to make brownfield regeneration more attractive but rarely consider their sustainability. Deciding how to regenerate brownfields should involve more than redeveloping the site to meet regulations or to meet a predetermined site use. Member states, policy makers, land owners and developers need to understand all aspects of brownfield regeneration and how sustainability issues need to be paramount in choosing alternative site uses [6].

No legal standards for soil quality have been set at the EU level but targets have been set by some member countries. In general legislation aims at preventing new contamination and setting targets for the remediation of sites where environmental standards have already been exceeded.

A number of activities causing soil pollution can be clearly identified across Europe. These relate, in particular, to losses during industrial activities and to waste disposal from municipal and industrial sources. However the range of polluting activities varies considerably from country to country. The variation may be the result of differing classification schemes or due to incomplete reporting.

The implementation of existing legislative and regulatory frameworks (Integrated Pollution Prevention and Control Directive, Landfill Directive, Water Framework Directive) should result in less new contamination of soil. However efforts are still needed to deal with historical contamination.

\section{Application of damage factors developed by EcoIndicator99}

Eco-indicators 99 is a damage-oriented method for Life Cycle Impact Assessment (LCA) in production and consumption patterns in Europe [7]. The group of experts has developed damage models for the most important 
environmental impact categories. The methodology report from 2001 includes extensive list of substances' damage factors that can be found in most popular LCA databases. The expert panel has categorized and weighted the following three types of environmental damages: human health, ecosystem quality and resources.

The human health damages are specified in DALYs. This is short for Disability Adjusted Life Years. A damage of 1 means one life year of one individual is lost, or one person suffers four years from a disability with a weight of 0.25. All damage factors are expressed per $\mathrm{kg}$ emission. Fate factors are calculated with EUSES (European Union System for the Evaluation of Substances). For the fate and exposure it is important to distinguish emission to soil between emissions in industrial or agriculture soil. The brownfield studies assume that all emissions occur in industrial (or urban) soil.

Damage to Ecosystems Quality is expressed as the percentage of species that have disappeared in a certain area due to the environmental load. The Ecosystem Quality damages are specified as $\mathrm{PDF}^{*} \mathrm{~m}^{2}$ year. PDF is short for Potentially Disappeared Fraction of Species. A damage of one means all species disappear from one $\mathrm{m}^{2}$ during one year, or $10 \%$ of all species disappear from $10 \mathrm{~m}^{2}$ during one year, or $10 \%$ of all species disappear from $1 \mathrm{~m}^{2}$ during 10 years. Fate analysis was done in EUSES. All damage factors are expressed per kg release.

Since the authors of this article have considered only local effects, the following categories of impacts are defined: i) carcinogenic effects on human health; ii) respiratory effects on human health caused by organic compounds; iii) respiratory effects on human health caused by inorganic compounds; iv) damage to ecosystem quality caused by ecotoxic emissions; v) damage to ecosystem quality caused by combined effects of acidification and eutrophication.. It should be noted that global effects on human health, such as climate change, ozone layer depletion also could be taken into consideration.

Due to the high complexity of the issue, authors have limited themselves by giving an example of damage factors of heavy metals, i.e. estimated local effects to human health and damage to ecosystems quality. Numerous studies point out that $\mathrm{Ni}, \mathrm{Cd}, \mathrm{Cr}$, As make carcinogenic effects on human health, respectively

Table 1: $\quad$ The damage values of heavy metals.

\begin{tabular}{|r|c|c|c|c|c|c|l|}
\hline $\begin{array}{l}\text { Heavy } \\
\text { metals }\end{array}$ & $\mathrm{Fe}$ & $\mathrm{Cu}$ & $\mathrm{Zn}$ & $\mathrm{Ni}$ & $\mathrm{Hg}$ & $\mathrm{Cd}$ & $\mathrm{Cr}(\mathrm{VI})$ \\
\hline \multicolumn{7}{|c|}{ Carcinogenic effects on human health (DALYs) } \\
\hline Air & - & - & - & $2.35 \mathrm{E}-02$ & - & $1.35 \mathrm{E}-01$ & 1.75 \\
\hline Water & - & - & - & $3.11 \mathrm{E}-02$ & - & $7.12 \mathrm{E}-02$ & $3.43 \mathrm{E}-01$ \\
\hline Soil & - & - & - & $3.94 \mathrm{E}-03$ & - & $3.98 \mathrm{E}-01$ & $2.71 \mathrm{E}-01$ \\
\hline
\end{tabular}


ecotoxic emissions of $\mathrm{Fe}, \mathrm{Cu}, \mathrm{Zn}, \mathrm{Ni}, \mathrm{Hg}, \mathrm{Cd}, \mathrm{Cr}(\mathrm{VI})$, As make damage to ecosystem quality. Thus, contamination by heavy metals causes two categories of damages: carcinogenic effects on human health and degradation of ecosystem quality caused by ecotoxic emissions.

Heavy metals generally found in contaminated soils include iron (Fe), copper $(\mathrm{Cu})$, zinc $(\mathrm{Zn})$, nickel $(\mathrm{Ni})$, mercury $(\mathrm{Hg})$, cadmium $(\mathrm{Cd})$, chromium $(\mathrm{Cr})$ and arsenic (As). The damage factors of the same metal found in different media (air, water, soil) could vary considerably, table 1 . It should be noted that the same metal has different influence on human health and ecosystems.

\section{Emission-damage factors assessment}

Authors have introduced composite entity, which comprises qualitative and quantitative characteristics of vehicular emissions. The weight emda (emissions + damage) was derived in order to estimate impacts of vehicular emissions on human health and ecosystems. On the common basis the emda can be used to describe any chemical. Emda is not a scalar, but a vector, which means that composite entity, has not only magnitude, but also the direction. The emda value is estimated as vector summation of two constituents in perpendicular axes, fig. 3. Each emda vector is comprised of emission and damage vectors. As a result, emda could be applied vector algebra as well as operations of mathematical physics. In other words, "vector approach" extends analytical possibilities if compare to scalar values.

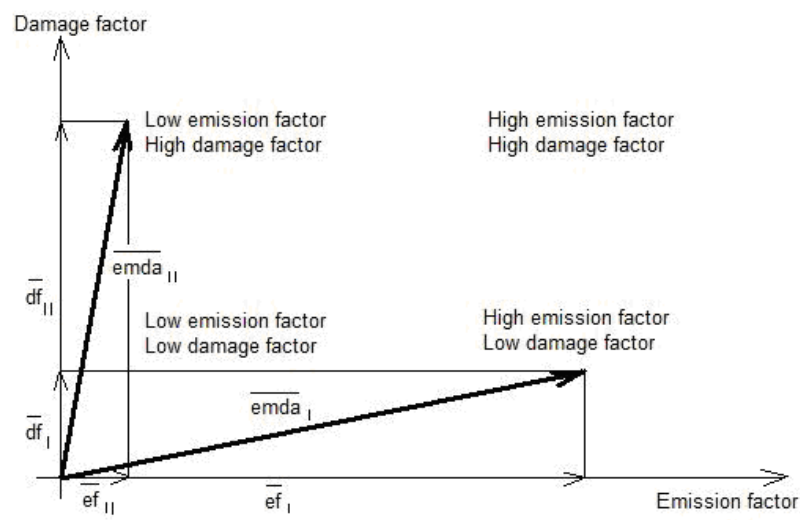

Figure 3: Identifying impact significance.

Substances that evaporate from the soil during application must be counted as air emissions. Substances that get into the surface waters must be counted as water emissions. The remainder must be counted as soil emissions. This means that calculations of overall emission- damage vector should be based on mass balance approach, fig 4.

No universally accepted definition for impact aggregation stands out. It is obvious, that aggregation is part of the assessment process. It is also evident that 


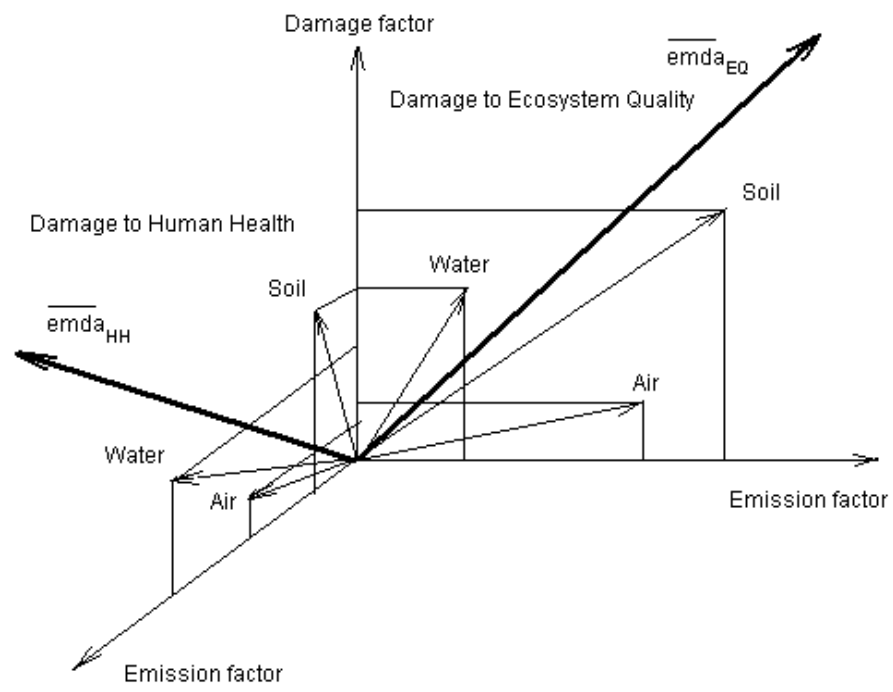

Figure 4: Schematic view of impacts on Ecosystem Quality and Human Health.

aggregation is close to the final stages of decision-making and, thence, it can be seen to an aid to those responsible of the final decision.

\section{Conclusions}

The authors have introduced emda vector approach for human health and ecosystem quality assessment. It should be noted, that each emda vector is composed by three components, i.e. emission-damage factors for soil, water and air.

The method of aggregation of emissions and damage factors in the form of vectors provides the new approach to the integrated assessment of environmental impacts in brownfield redevelopment.

The study has showed that damage oriented database for Life Cycle Impact Assessment (LCA) Eco-indicator'99 could be applied to estimate degree of potential damage on human health and ecosystems quality. The particular example on damage factors derived for contamination by heavy metals gives prerequisites for further development of environment health risk assessment method.

\section{Acknowledgement}

The study was performed in the frame of Leonardo Da Vinci project Brownfields in the Baltic States (BRIBAST), grant agreement No CZ/08/LLP$\mathrm{LdV} / \mathrm{TOI} / 134005$. The authors of the study express sincere gratitude to the project partners for advice and consultations. 


\section{References}

[1] Zhu Y., Hipel K. W., Life span risk management in brownfield redevelopment. IEEE Xplore, pp. 4052-4056, 2007.

[2] Feldman, L., Risk management at a brownfields site: a case study in longterm stewardship. Proc. of the $2^{\text {nd }}$ Int. Conf. On Prevention, Assessment, Rehabilitation and Development of Brownfields, eds. A. Donati, C. Rossi, C. A. Brebbia, Wessex Inst. Technol.: Siena, pp. 63-71, 2004.

[3] Arulanantham, R., Brewer, R., Expediting risk-based cleanup decisions at brownfields sites-chemical specific look-up tables. Proc. of the $2^{\text {nd }}$ Int. Conf. On Prevention, Assessment, Rehabilitation and Development of Brownfields, eds. A. Donati, C. Rossi , C. A. Brebbia, Wessex Inst. Technol.: Siena, pp. 159-169, 2004.

[4] European Environment Agency, CSI 015 - Progress in management of contaminated sites - Assessment published, Jul. 2005. http://themes.eea. europa.eu/IMS/IMS/ISpecs/ISpecification20041007131746/IAssessment111 6497286336/view_content

[5] European Environment Agency, CSI 015 - Progress in management of contaminated sites - Assessment published, Aug. 2007. http://themes.eea. europa.eu/IMS/IMS/ISpecs/ISpecification20041007131746/IAssessment115 2619898983/view_content

[6] Thornton G., Franz M., Edwards D., Pahlen G, Nathanail P., The challenge of sustainability: incentives for brownfield regeneration in Europe. Environmental Science \& Policy, 10, pp. 116-134. 2007.

[7] The Eco-indicator 99, Manual for Designers. http://users.rowan.edu/ reverett/courses/soclii/LCA/EI99_manual_v3.pdf 